\title{
Impact of a Research Experience Program in Aerospace Engineering on Un- dergraduate Students: Year Two
}

\section{Dr. Jacques C. Richard, Texas A\&M University}

Dr. Richard got his Ph. D. at Rensselaer Polytechnic Institute, 1989 \& a B. S. at Boston University, 1984. He was at NASA Glenn, 1989-1995, worked at Argonne National Lab, 1996-1997, taught at Chicago State University, 1997-2002. Dr. Richard is a Sr. Lecturer \& Research Associate in Aerospace Engineering @ Texas A\&M since 1/03. His research is focused on computational plasma modeling using spectral and lattice Boltzmann methods for studying plasma turbulence and plasma jets. His research has also included fluid physics and electric propulsion using Lattice-Boltzmann methods, spectral element methods, Weighted Essentially Non-Oscillatory (WENO), etc. Past research includes modeling single and multi-species plasma flows through ion thruster optics and the discharge cathode assembly; computer simulations of blood flow interacting with blood vessels; modeling ocean-air interaction; reacting flow systems; modeling jet engine turbomachinery going unstable at NASA for 6 years (received NASA Performance Cash awards). Dr. Richard is involved in many outreach activities: e.g., tutoring, mentoring, directing related grants (for example, a grant for an NSF REU site). Dr, Richard is active in professional societies (American Physical Society (APS), American Institute for Aeronautics and Astronautics (AIAA), etc.), ASEE, ASME. Dr. Richard has authored or co-authored about 35 technical articles (about 30 of which are refereed publications). Dr. Richard teaches courses ranging from first-year introductory engineering design, fluid mechanics, to space plasma propulsion.

\section{Dr. So Yoon Yoon, Texas A\&M University}

So Yoon Yoon, Ph.D., is an associate research scientist at Institute for Engineering Education and Innovation (IEEI) in College of Engineering at Texas A\&M University and Texas A\&M Engineering Experiment Station (TEES). She received a Ph.D. in Educational Psychology with specialties in Gifted Education and a M.S.Ed. in Educational Psychology with specialties in Research Methods and Measurement both from Purdue University. She also holds a M.S. in Astronomy and Astrophysics and a B.S. in Astronomy and Meteorology both from Kyungpook National University in South Korea. Her work centers on engineering education research, as a psychometrician, program evaluator, and institutional data analyst. She has research interests on spatial ability, creativity, gifted education, STEM education, and meta-analyses. She has authored/co-authored more than 50 peer-reviewed journal articles and conference proceedings and served as a journal reviewer in engineering education, STEM education, and educational psychology, as well as a co-PI, an external evaluator or advisory board member on several NSF-funded projects (CAREER, iCorps, REU, RIEF, etc.). 


\title{
Impact of a Research Experience Program in Aerospace Engineering on Undergraduate Students: Year Two
}

\begin{abstract}
This work-in-progress study is to report results from the second-year implementation of research experiences for undergraduates (REU) program funded by the National Science Foundation (NSF) in aerospace engineering at a Southwestern public research university. A total of 25 students, who are citizens or permanent residents selected across the United States, participated in the REU program for 10 weeks during the summer in 2017 or 2018 . This study utilized the data from 19 out of the 25 students who responded to both pre- and post-surveys ( $76 \%$ response rate) to present student changes in career decision making and research experiences at the university. Most students came to favor graduate education and research and their preferences did not change after the REU program. Students' perceptions of research knowledge, skills, and engineering career path were all positively improved. We also identified several areas of research skills that students were able to amass during the programs.
\end{abstract}

\section{Introduction}

The National Science Foundation (NSF) has been among the federal governmental institutions that strongly support summer research programs as a means of attracting undergraduate students into graduate education and research. Through research experiences for undergraduates (REU) programs, NSF supports U.S. citizens and permanent resident students from institutions that may not have graduate programs in an area to immerse them into research environment at a host research university. Therefore, REU programs are aimed to increase participants' awareness and interest in graduate school in computing, science, technology, engineering, and math (C-STEM) fields.

However, the recent data showed the continuing lack of diversity in engineering graduate programs [1]. From 2007 to 2017, there was a 5.1\% increase in total graduate enrollment of women in engineering, but Figure 1 shows that engineering graduate enrollment remained heavily dominated by men $73.5 \%$. However, there has been slight improvement in minority engineering graduate enrollment. The largest improvement has been for Hispanic graduate enrollment in engineering (9.5\% from 2007 to 2017). African Americans showed only a 2.5\% increase. The only group with a decrease in enrollment was American Indians/Alaska Natives with a change of $-2.9 \%$. Asian/Pacific Islander and White graduate enrollment each showed an increase of $1.9 \%$. Despite positive improvements in minority graduate enrollment in engineering, White is still dominant with $63.2 \%$. This profile indicates need for continuous efforts to improve diversity. 


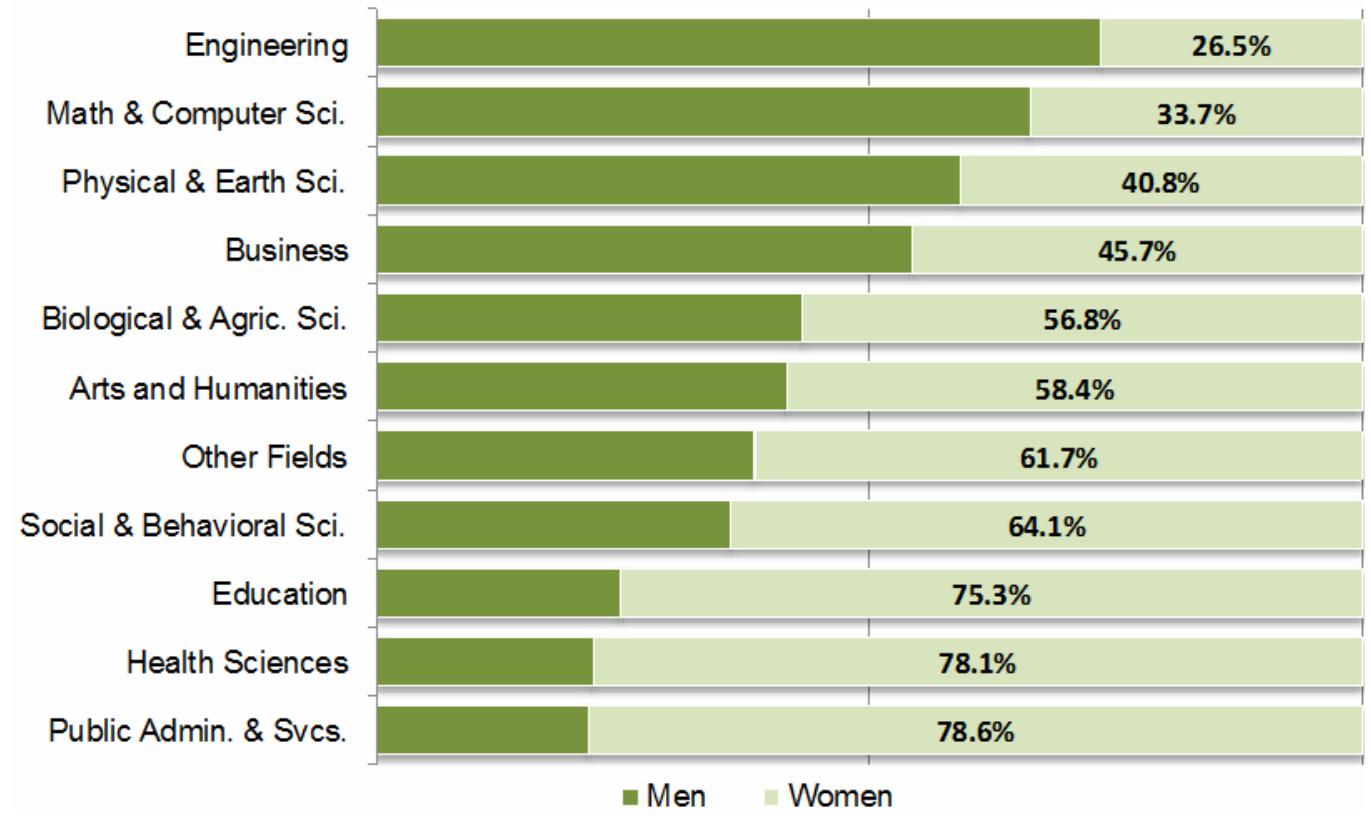

Figure 1. First-time graduate enrollment by gender [1, pp. 12]

Among various engineering disciplines, aerospace engineering tended to have relatively small numbers of underrepresented women and minorities. According to Digest of Education Statistics 2017 [2], graduate enrollment in research-based aerospace engineering programs increased 17\% from 4,616 in 2007 to 5,416 in 2016 in 10 years. However, the numbers of students with master's and doctor's degrees in aerospace engineering in 2015-2016, conferred by postsecondary institutions, were 2,027 (83.5\%) for male students and $402(16.5 \%)$ for female students, which still presents significant gender disparity.

More specifically, women earning master's degrees in aerospace engineering were at $15.8 \%$, which is at the bottom five of the degree earning among all disciplines. Women earning doctoral degrees in aerospace engineering were at 17.5\%, and this was also at the bottom five in 2016 [3]. The numbers of women and underrepresented minority faculty in aerospace engineering were also dismal among tenured/tenure-track faculty. Women faculty were at $9.8 \%$ in the bottom five of all disciplines and African-American faculty were at $2.0 \%$ in the bottom five of all disciplines. Hispanic faculty were the only minority that was not in the bottom five of all disciplines with $3.1 \%$, but the fact is not exemplary either for adequate numbers to serve as role models in aerospace engineering. Considering that underrepresented faculty could help recruit underrepresented students in aerospace engineering, these trends are not desirable.

Under these circumstances, this study explored the impacts of a summer REU program on diverse students supported by NSF in the Department of Aerospace Engineering at a Southwestern public research university.

\section{A. Benefits of Undergraduate Research Experiences}

Studies showed that research experiences for undergraduates (REU) were very effective in broadening participation in graduate school and research [4] - [9]. Several studies observed up to 
a $60 \%$ increase in participants, eventually attending graduate or professional education [10] [13]. Sadler \& McKinney [14] noted undergraduate students' increases in graduate education interest, building research skills, and confidence in research. Studies found that students who participated in REU programs acknowledged the value of the role of the faculty mentor [13], [15], [16]. Perez and Gong [17] found that the main factors impacting minority students' access to graduate school included cost, knowledge of available graduate programs, understanding of graduate study and research in general, and career relevance of the graduate degree options.

\section{B. Purpose of the Study}

A main purpose of this study was to explore the impacts of undergraduate students' research experiences on their perceptions of career goals, graduate school, research knowledge and skills, and engineering career path at a Southwestern public research university in the United States (US). The following research questions guided this study.

1. How does the REU influence students' career goals?

2. How does the REU affect students' self-efficacy of making decision about graduate school and success therein?

3. How does the REU affect students' preferences on research type?

4. How does the REU change participants' perceptions of their research knowledge, skills, and engineering career path?

\section{Method}

\section{A. Setting}

Objectives of the REU Program. The specific objectives of the REU program at the university were to (a) engage a minimum of 10 undergraduates annually; (b) prepare the students for graduate school through workshops on the Graduate Record Examinations (GRE), increasing awareness of graduate opportunities, strengthening of resumes by publishing research, and improving written and oral communication; and (c) measure the effectiveness of the REU program in encouraging students to attend graduate school. The selected undergraduates were to include at least $60 \%$ women and underrepresented minorities, in rich summer aerospace engineering (AERO) research experiences at a tier-one research university, recruited mainly from minority-serving and predominantly undergraduate institutions.

REU Program Recruitment. While students can get information on the REU program from the AERO REU website at the university, most of them found out about it from the NSF website. The REU program coordinator also emailed flyers to faculty at different supporting universities or travelled to several universities within driving distance to personally recruit students. The program coordinator reviewed the online applications with a few interested AERO faculty members, then selected and matched top applicants with the faculty members who share mutual areas of interests. This meant that not one single factor (GPA, letters of recommendation, essays, and transcripts, etc.) dominated the reason for selection.

Program Structure and Activities. The 10-week AERO REU program at the research university involved several components: (1) matching participants with faculty for direct hands- 
on training in relevant computational and experimental research methods, (2) participation in research-oriented field trips (e.g., various labs on campus, Ad Astra Rocket Co., and NASA Rocket Park, etc.), (3) participation in professional-development workshops (e.g., GRE, technical writing, etc.), and (4) presenting formal research papers at professional conferences and submitting to refereed journals.

The AERO REU program was coordinated with the college's own summer programs. The college summer research program engaged undergraduate engineering students in graduate-type projects under the supervision of faculty researchers. By linking to these programs, the AERO REU students together with other departmental REU students could take advantage of an extensive supporting infrastructure, such as professional development (e.g., workshop, seminars, and end-of-program symposium) and social activities (welcome breakfast, picnics, barbecues, attending sporting events, participating in recreational activities, and tours).

\section{B. Participants}

A total of 25 students, who are citizens or permanent residents selected across the United States, participated in the REU program for 10 weeks during the summer in 2017 or 2018 . While 24 students responded to either pre- or post-surveys, this study utilized the data from 19 students who responded to both pre- and post-surveys ( $76 \%$ response rate) to present student changes in perceptions of career decision making and research as the impact of the REU program at the university.

Table 1. Demographic Characteristics of Survey Respondents from Summers of 2017 and 2018

\begin{tabular}{llcc}
\hline \multirow{2}{*}{ Category } & \multirow{2}{*}{ Subcategory } & \multicolumn{2}{c}{ Total } \\
\cline { 3 - 4 } Gender & Female & 7 & 36.8 \\
& Male & 12 & 63.2 \\
& & & \\
Race/ & Hispanic & 4 & 21.1 \\
Ethnicity & American Indian or Alaska Native & 1 & 5.3 \\
& Asian & 0 & 0.0 \\
& Black & 3 & 15.8 \\
& White & 11 & 57.9 \\
Student & Sophomore & 4 & 21.1 \\
Level & Junior & 8 & 42.1 \\
& Senior & 7 & 36.8 \\
\hline Total & & 19 & 100.0 \\
\hline
\end{tabular}

\section{Measures}

We utilized pre- and post-surveys for the REU participants to assess the impact of the REU programs on their career goals and research experiences. The areas of assessments in the presurvey included career goals after graduation, self-efficacy in decision making toward a graduate school, motivation to apply for the REU program, prior research experiences, research expectations, perceptions of research knowledge, skills, and engineering career paths, and the 
REU program admission logistics. The post-survey inquired about the items in the pre-survey to follow up, and additionally items about research skills learned from the REU program, summary of the research project, engagement with the project, and overall experiences with the REU program.

We analyzed several common items on both pre-post surveys, aligned with the NSF REU program objectives, such as career goals after graduation, self-efficacy in decision-making toward graduate school and for success in graduate school. We also analyzed preferences on research type, perceptions of research knowledge, skills, and engineering career paths. The format of the measures varied, including open-ended questions, ranking, and seven-point Likertscales, ranging from 1 (strongly disagree) to 7 (strongly agree).

\section{Data Analyses}

For quantitative data on the Likert-scales, we only applied descriptive statistics, such as mean and standard deviation, due to the small number of respondents for both pre- and post-surveys. For qualitative data on the open-ended questions on research skills that students wanted to learn on the pre-survey and acquired on the post-survey, two researchers of this study closely scrutinized students' raw responses to supplement details in the change of participants' perceptions appeared in the Likert-scales [18], [19].

\section{Results}

\section{A. Effects of the REU on Career Goals}

For all respondents $(N=19)$, Figure 2 shows that almost all students started with interest in graduate school. Note that students could select multiple options, such as both graduate school and job. There was a minute drop at the end, indicating that some students lost interest in attending graduate school. Less than half of the students at the start of the program wanted a job after graduation and this trend did not change after the REU program. The trend for the undecided students did not change either.

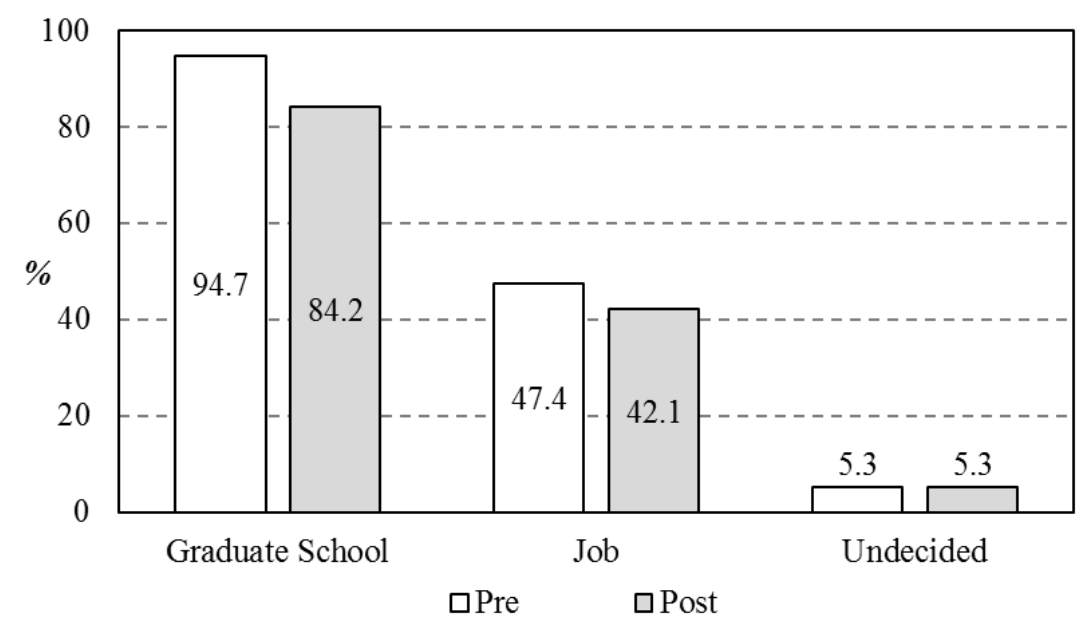

Figure 2. Changes in student career goals after graduation $(N=19)$ 


\section{B. Effects of the REU on Self-efficacy about Graduate School}

There was no significant change in any influence of the program on the participants' selfefficacy of decision-making toward graduate school, according to the results plotted in Figure 3. There was no significant change in their self-efficacy for the success in graduate school either.

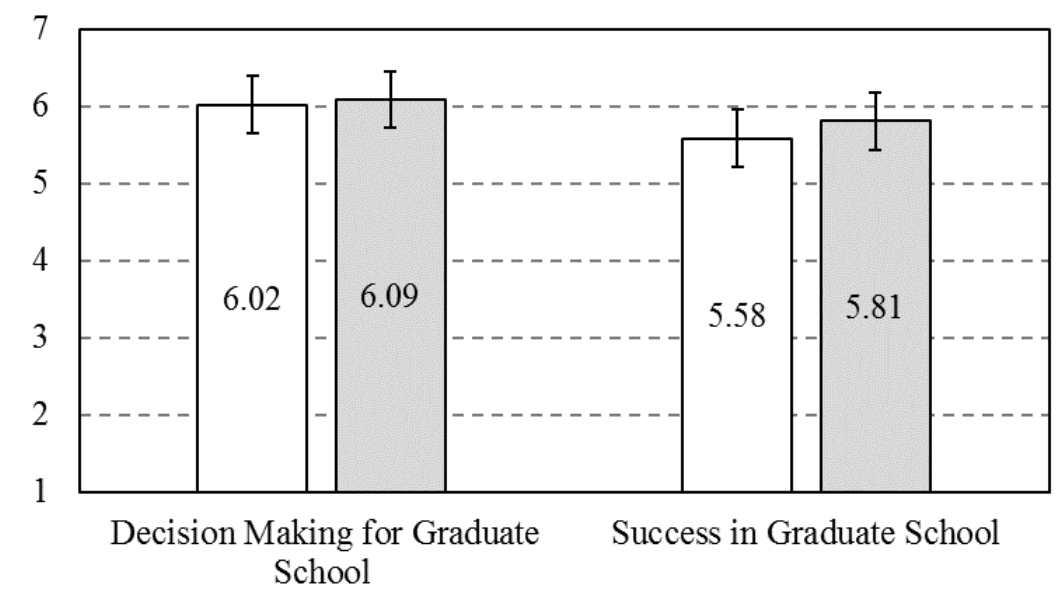

$\square$ Pre $\quad \square$ Post

Figure 3. Impact of the REU program on student self-efficacy on graduate school

\section{Preferences on Research Type}

Figure 4 shows the changes in student preferences on research types. There were few changes except that interest in both computational and experimental research arose. A positive take-away is that the number of students who were not able to decide their preference dropped by a factor of three indicating that the REU program may have helped them decide.

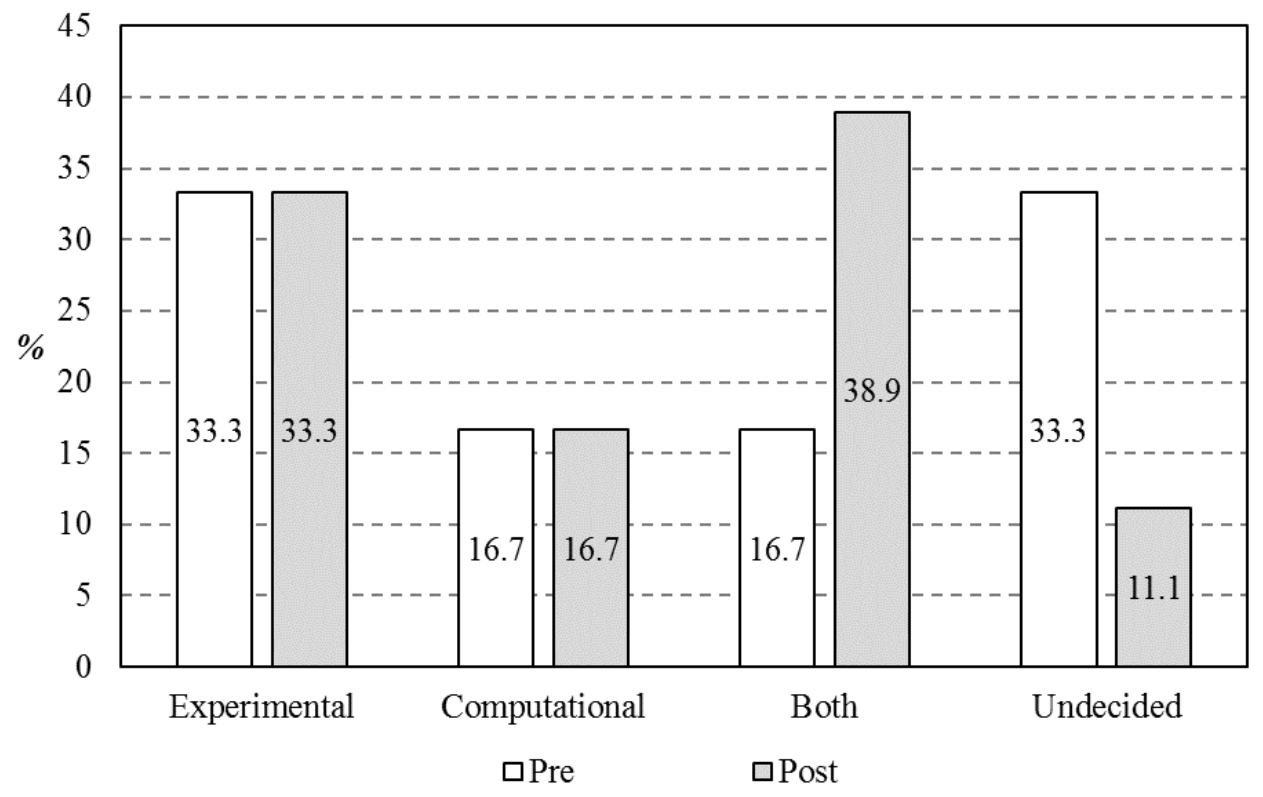

Figure 4. Changes in Preferences on Research Types $(n=18)$ 


\section{Effects of the REU on Students' Research knowledge, skills, and Engineering Career Path}

Figure 5 shows the increases in student perceptions of research knowledge, skills, and engineering career paths. The fact that they all increased is a positive indicator of the REU effects on students, helping them decide on their career.

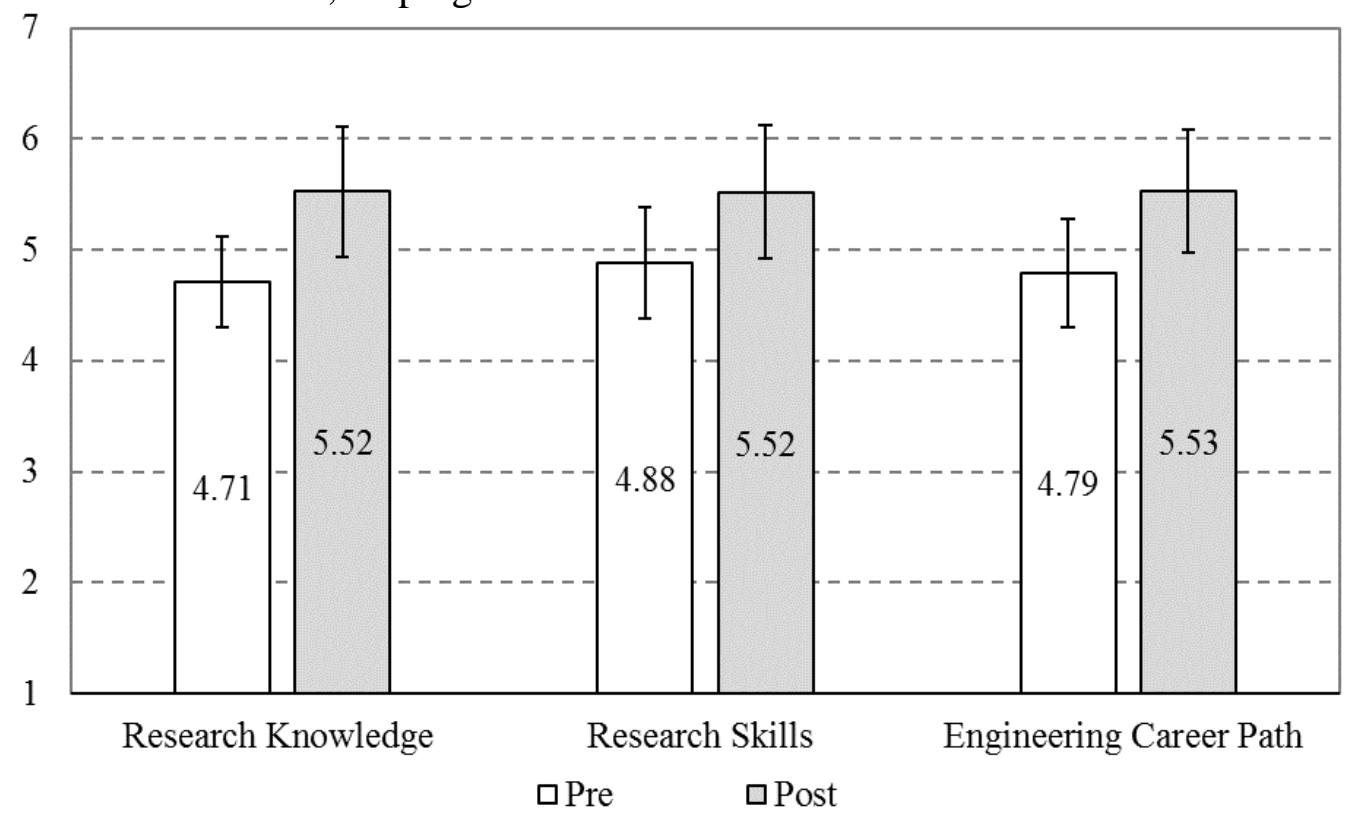

Figure 5. Impact of the REU program on student perceptions of research knowledge, skills, and engineering career path $(n=18)$

As shown in Figure 6, there were two overarching common themes that emerged from openended questions on the research skills to acquire on the pre-survey and the research skills acquired through the REU program on the post-survey: hard and soft skills. Hard skills that students mentioned were fundamental knowledge acquisition, practice of techniques/skills, and how to do research. Soft skills that students addressed were higher-order thinking skills, communication, teamwork, professionalism, and networking. Higher-order thinking skills that students addressed include analytical, critical, problem solving skills and creativity. Communication includes communication skills with peers, research teams, and people from different disciplines of research, presentation of the research through posters, and writing skills. Professionalism includes persistence, patience, confidence, independence or autonomy, and time management.

Among hard skills, Figure 6 shows that acquiring knowledge decreased from $41 \%$ to $6 \%$, while getting practice of specific techniques or skills increased and almost doubled. There was no significant change in how to do research. Figure 6 also shows that some soft skills did have big changes. Higher-order thinking skills decreased by $18 \%$. More than half of students (59\%) expected to acquire communication skills before the program and the similar percent of students (53\%) expressed improved communication skills through the program. However, $18 \%$ of students expected to develop teamwork skills but only $6 \%$ of students mentioned improvements of teamwork skills. Among the soft skills, professionalism was the area that students expressed 
as the most gained (77\%) compared to their expectations on the pre-survey (41\%). Although $29 \%$ of students expected to acquire networking skills, no one mentioned it on the post-survey.

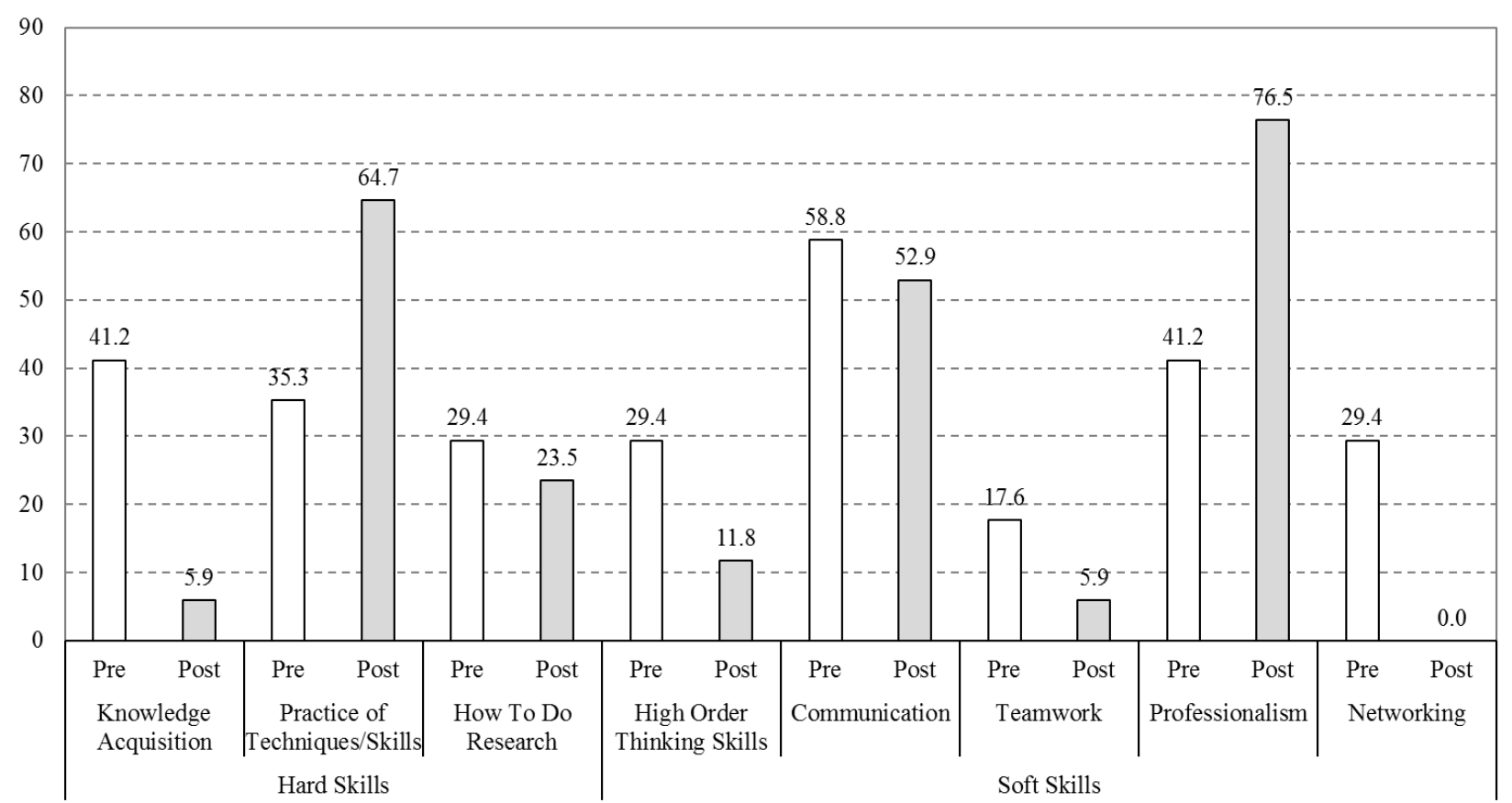

Figure 6. Student expectations on research skills to acquire on the pre-survey and their acquiring of research skills on the post survey $(n=17)$

\section{Discussion}

This study explored the influence of summer research experiences in aerospace engineering on 19 domestic undergraduate students at a Southwestern public research university. Using pre- and post-surveys, we explored any changes before and after the REU program during 2017 and 2018, in terms of career goals, self-efficacy of graduate school, perceptions of research knowledge, skills, engineering career path, preferences in research type, and research expectation/experiences. The findings from the two years data on career goals, self-efficacy, and perceptions showed similar patterns from the one year data [20]. To supplement quantitative findings, we quoted from students' responses to the open-ended questions and from comments on the programs.

\section{A. Career Goals}

Though survey data presented no distinctive changes, the REU program seemed to provide opportunities to learn more about the engineering discipline and specify their career goals as studied by Morley et al. [11]. One student stated that:

"This REU challenged me to find my passion in specific fields of engineering. Yes, I knew I loved Aerospace Engineering. But it wasn't until this REU where I was able to sample all the different sub-fields and determine which I wanted to specialize in." 


\section{B. Self-efficacy about Graduate School}

Although we found no distinctive changes in student self-efficacy of making decision toward graduate school and success therein, the REU seemed to provide an opportunity to learn about what graduate school looks like [4], [9], [14]. One student mentioned the value of graduate school and REU as:

"I learned that I do not know anything yet. Real, hands-on education seems to come during graduate school, and it seems that undergraduate research simply prepares for that."

Another student stated learning about "How to apply for graduate school and what research opportunities there are at [the university]."

\section{Perceptions of Research Knowledge, Skills, and Engineering Career Path}

Along with the increase in student perceptions of research knowledge, skills, and engineering career path as shown in Figure 4, the open-ended responses revealed the specific areas of their research knowledge and skills that they improved [4]. For example, pre-survey data showed students expected to have various research experiences and to grow in their knowledge acquisition, skills, and how to conduct research in general. However, on the post-survey, students were able to be more specific about the knowledge and skills that they acquired through the REU program. For example, a student expected to learn about coding on the pre-survey, but on the post-survey, the student specified learning of coding in a particular language (e.g., $\mathrm{C}++$ ). Clearly, the REU changed the students' perceptions of knowledge and skills.

Among hard skills, one finding is the significant decrease on acquisition of research knowledge from the expectations by $41 \%$ of students to experience of the improvement by $6 \%$ of students. Instead, acquiring practice of techniques or skills almost doubled.

Regarding soft skills, professionalism was the only area with an increase. For example, a student mentioned: "I learned that I am a harder worker than I thought I was and that I will continue to work until the very end if it means finally getting some result." Another student stated that "Being able to deal with setbacks in a 10-week research program and there are so many more discoveries to be made through research." Regarding networking, one student expressed the value of networking on the post-survey as such: "It helped me make career decisions. I also got to meet a lot of people from different cultures which gave me immense insight. It was a great research and networking experience."

One important lesson from the findings on hard and soft skills is that an REU can be more intentional in designing to build such skills together, as both skills are addressed as important in the ABET Student Outcomes. Even though the REU programs at the Southwestern public research university have already incorporated workshops for communication skills, the findings of this study identified other skills that warrant more proactive workshops, such as including professionalism and networking. Then, the REU program can be strengthened even though students come to do research with expectations that they will build associated hard skills. 


\section{Limitations of the Study and Future Research}

Through various types of measures on the surveys, this study revealed changes in student perceptions of career goals, research knowledge, skills, and engineering career path, and students' research expectations and experiences after the REU program. However, there are several limitations in this study that warrant future research. The small sample size and the unique learning and research environment at the university limit the generalizability of the findings beyond the scope of this study. Therefore, there is a need to increase the sample size to increase statistical power for future research and explore any differences in their perceptions and experiences between student characteristics, such as by gender and racial/ethnic groups. Second, the scales used to assess student self-efficacy on graduate school and perceptions of research knowledge, skills, and engineering career path were not validated yet due to the small sample size. Further research is necessary to validate those scales with a larger sample size. Third, this study only explored cross-sectional effects of the program on student career goals and research outcomes. Therefore, there is a need of a longitudinal study, tracking participants' career changes after undergraduate graduation, such as graduate enrollment in engineering, and research activities, such as presentations at a conference and publications in a journal.

\section{Acknowledgement}

We conducted this work under the auspices of the National Science Foundation (NSF) under grant number EEC-1560424. However, any views expressed in this paper do not necessarily represent those of NSF or its affiliates.

\section{References}

[1] H. Okahana, and E. Zhou, Graduate enrollment and degrees: 2007 to 2017. Washington, DC: Council of Graduate Schools, 2018.

[2] T. D. Snyder, C. de Brey, and S. A. Dillow, Digest of Education Statistics 2017 (NCES 2018070). Washington, DC: National Center for Education Statistics, Institute of Education Sciences, U.S. Department of Education, 2019.

[3] B. L. Yoder, Engineering by the numbers. American Society for Engineering Education (ASEE), 2016. Retrieved from https://www.asee.org/documents/papers-andpublications/publications/college-profiles/16Profile-Front-Section.pdf

[4] A.-B. Hunter, S. Laursen, and E. Seymour, "Becoming a scientist: The role of undergraduate research in students' cognitive, personal and professional development," Science Education, vol. 91, no.1, pp. $36-74,2006$.

[5] K. Karukstis, "The Impact of undergraduate research on America's global competitiveness," Journal of Chemical Education, vol. 84, no. 6, pp. 912-914, 2007.

[6] National Academies of Sciences, Engineering, and Medicine. Undergraduate research experiences for STEM students: successes, challenges, and opportunities. Washington, DC: The National Academies Press, 2017.

[7] National Academies of Sciences, Engineering, and Medicine. Graduate STEM Education for the $21^{s t}$ Century. Washington, DC: The National Academies Press, 2018.

[8] S., Russell, M. Hancock, and J. McCullough, The Pipeline: Benefits of Undergraduate Research Experiences, Science, vol. 316, pp. 548 - 549, 2007. 
[9] E. Seymour, A. E., Hunger, S. A., Laursen, S., and T. DeAntoni, Establishing the Benefits of Research Experiences for Undergraduates in Sciences: First Finding from a Three-Year Study. Science Education, vol. 88, no. 4, pp. 493-534, 2004.

[10] S. J. Grimberg, T. A. Langen, L. D. Compeau, and S. E. Powers, A theme-based seminar on environmental sustainability improves participant satisfaction in an undergraduate summer research program. Journal of Engineering Education, vol. 97, no. 1, 95-103, 2008.

[11] R. L. Morley, J. J. Havick, and G. S. May, An evaluation of the Georgia Tech summer undergraduate program of research in electrical engineering for minorities. Journal of Engineering Education, vol. 87, no. 3, pp. 321-325. 1998.

[12] M. C. Page, C. I. Abramson, and J. M. Jacobs-Lawson, The National Science Foundation Research Experiences for Undergraduates Program: Experiences and recommendations. Teaching of Psychology, vol. 31, no. 4, pp. 241-247, 2004.

[13] A. L. Zydney, J. S. Bennett, A. Shahid, and K. W. Bauer, Impact of undergraduate research experience in engineering. Journal of Engineering Education, vol. 91, no. 2, pp. 151-157, 2002.

[14] T. D. Sadler, and L. McKinney, Scientific research for undergraduate students: A review of the literature. Journal of College Science Teaching, vol. 39, pp. 43-49, 2010.

[15] D. Morales, S. Grineski, and T. Collins, Increasing research productivity in undergraduate research experiences: exploring predictors of collaborative faculty-student publications. CBE - life sciences education, vol. 16, no. 3, pp. 1-9, 2017.

[16] D. Morales, S. Grineski, and T. Collins, Faculty motivation to mentor students through undergraduate research programs: a study of enabling and constraining factors. Research in Higher Education, vol. 58, no. 5, pp. 520-544, 2017.

[17] V. H. Perez, and T. Gong, Increasing Minority Students' Access to Graduate Schools. InterActions: UCLA Journal of Education and Information Studies, vol. 1, no. 2, 2005

[18] M. Q. Patton, Qualitative evaluation and research methods. (3rd ed.). Newbury Park, CA: Sage, 2002.

[19] D. R. Thomas, A general inductive approach for analyzing qualitative evaluation data. American Journal of Evaluation, vol. 27, pp. 237-246, 2006.

[20] J. C. Richard and S. Y. Yoon, "Impact of undergraduate research experiences on diverse national and international undergraduate researchers". Proceedings of the $125^{\text {th }}$ American Society for Engineering Education (ASEE) Annual Conference and Exposition, Salt Lake City, UT, USA, 2018. 